
p. 69-71, março 1999.

\title{
Controle pós-emergente de plantas daninhas em cenoura.
}

\author{
Jeferson Zagonel; Marie Yamamoto Reghin; Wilson Story Venâncio \\ Universidade Estadual de Ponta Grossa, Praça Santos Andrade s/n, 84.010-790, Ponta Grossa-PR.
}

\section{RESUMO}

O experimento foi conduzido em Piraí do Sul-PR no ano de 1995 em solo de textura argilo arenosa, tendo como objetivo avaliar a eficiência e a seletividade do herbicida propaquizafop no controle pós-emergente de plantas daninhas na cultura da cenoura. O delineamento experimental utilizado foi de blocos ao acaso com seis tratamentos e quatro repetições, quais sejam: propaquizafop (100, 125 e $150 \mathrm{~g}$ i.a./ha); fluazifop-p-butil (188 g i.a./ha); testemunha capinada e testemunha sem capina. A cultivar de cenoura utilizada foi Nantes Tim Tom semeada em 15 de junho, com espaçamento de $0,25 \times 0,05$ $\mathrm{m}$, em parcelas com área útil de 5,00 x 1,00 m. As plantas daninhas predominantes foram Brachiaria plantaginea (capim-papuã), Digitaria horizontalis (capim-milhã) e Eleusine indica (capim péde-galinha). As avaliações foram efetuadas aos 15, 30 e 45 dias após a aplicação dos tratamentos. Observou-se que o herbicida propaquizafop, nas doses de 100, 125 e $150 \mathrm{~g}$ i.a./ha foi eficiente no controle sobre capim-papuã, capim-milhã e capim pé-de-galinha. O controle de plantas daninhas realizado através de herbicidas proporcionou a mesma produção obtida com o controle manual. A perda na produção ocasionada pela presença de plantas daninhas foi da ordem de $76,4 \%$. Não foram observados efeitos fitotóxicos nas plantas de cenoura que pudessem ser atribuídos aos produtos utilizados.

Palavras-chave: Daucus carota L., herbicidas, controle químico.

\begin{abstract}
Post-emergence weed control in carrot crop.

The presented field trial was conducted in 1995 in Piraí do Sul, Paraná State, Brazil, on a sand-clay texture soil, to evaluate the efficiency and selectivity of propaquizafop on carrot crop weed control. The experiment was laid out in a randomized block design with six treatments and four replications, and $5.00 \times 1.00 \mathrm{~m}$ plots. The treatmens were: propaquizafop $(100,125$ and $150 \mathrm{~g} \mathrm{a.i/ha);}$ fluazifop-p-butil (188 g a.i/ha); control with weeding and control without weeding. The carrot cultivar Nantes Tim Tom was sown on June 15 with plants spaced $0.25 \times 0.05 \mathrm{~m}$. The prevalent weeds were Brachiaria plantaginea (capim-papuã), Digitaria horizontalis (capim-milhã) and Eleusine indica (capim pé-de-galinha). Evaluations were carried out at 15,30 and 45 days after treatment applications. The herbicide propaquizafop, at doses 100, 125 and $150 \mathrm{~g} \mathrm{a.i} / \mathrm{ha}$, was efficient in control of capim-papuã, capim-milhã and capim pé-de-galinha. Weed control using herbicides resulted in the same production when compared to manual control. Production losses due to the presence of weeds was $76.4 \%$. Carrot plants did not show any visual symptoms of damage attributed to herbicide applications.
\end{abstract}

Keywords: Daucus carota L., herbicides, chemical control.

\section{(Aceito para publicação em 30 de novembro de 1998)}

\begin{abstract}
A cenoura é a principal hortaliça raiz, altamente consumida por sua riqueza em vitaminas e sais minerais. Atualmente é cultivada em grande escala, ocupando extensas áreas como em São Gotardo (MG) ou em Piraí do Sul (PR). A crescente escassez e valorização da mão-de-obra do meio rural, a disponi-
\end{abstract}

bilidade de herbicidas seletivos, eficientes no controle de várias espécies de plantas daninhas, além de outros fatores, tem contribuído para a divulgação do uso de herbicidas nesta olerícola. A cenoura caracteriza-se pela fragilidade de seus talos, pelo crescimento inicial lento e por uma excessiva população de plantas, o que torna reduzido seu poder de competição com plantas daninhas. Estes fatores tornam inviável o seu cultivo, quando se deixa de usar um método de controle de plantas daninhas. A não utilização de métodos de controle das plantas daninhas ou de técnicas culturais que tornem o mais precoce possí- 
Tabela 1.Avaliação visual de controle (\%) de herbicidas sobre plantas daninhas e produção de cenoura. Piraí do Sul-PR, UEPG, 1995

\begin{tabular}{|c|c|c|c|c|c|c|c|c|c|c|c|}
\hline \multirow{2}{*}{ Tratamentos } & \multirow{2}{*}{$\begin{array}{c}\text { Dose } \\
\text { i.a. }(\mathrm{g} / \mathrm{ha})^{2}\end{array}$} & \multicolumn{3}{|c|}{$15 \mathbf{D A A}^{1}$} & \multicolumn{3}{|c|}{$30 \mathbf{D A A}^{1}$} & \multicolumn{3}{|c|}{45 DAA $^{1}$} & \multirow{2}{*}{$\begin{array}{c}\text { Produção } \\
\text { (kg/ha) }\end{array}$} \\
\hline & & (1) & (2) & (3) & (1) & (2) & (3) & (1) & (2) & (3) & \\
\hline 1. Propaquizafop & 100 & $91,7 * a$ & $80,0 \mathrm{a}$ & 90,0 a & $90,0 \mathrm{a}$ & $90,0 \mathrm{a}$ & $90,0 \mathrm{a}$ & $91,0 \mathrm{a}$ & $85,0 \mathrm{a}$ & $86,7 \mathrm{a}$ & $23,3 \mathrm{a}$ \\
\hline 2. Propaquizafop & 125 & $93,0 \mathrm{a}$ & $85,0 \mathrm{a}$ & $94,0 \mathrm{a}$ & $91,7 \mathrm{a}$ & $91,7 \mathrm{a}$ & $92,6 \mathrm{a}$ & 93,0 a & 90,0 a & 90,0 a & $23,7 \mathrm{a}$ \\
\hline 3. Propaquizafop & 150 & $95,0 \mathrm{a}$ & $90,0 \mathrm{a}$ & $96,7 \mathrm{a}$ & 95,0 a & $95,0 \mathrm{a}$ & $94,5 \mathrm{a}$ & $93,2 \mathrm{a}$ & $93,0 \mathrm{a}$ & $93,2 \mathrm{a}$ & $23,8 \mathrm{a}$ \\
\hline 4. Fluazifop-p-butil & 188 & $95,0 \mathrm{a}$ & $75,0 \mathrm{a}$ & $95,0 \mathrm{a}$ & $93,2 \mathrm{a}$ & 90,0 a & $95,2 \mathrm{a}$ & $93,2 \mathrm{a}$ & $75,0 \mathrm{a}$ & $86,7 \mathrm{a}$ & $22,9 \mathrm{a}$ \\
\hline 5. Test. capinada & - & 100,0 & 100,0 & 100,0 & 100,0 & 100,0 & 100,0 & 100,0 & 100,0 & 100,0 & $24,1 \mathrm{a}$ \\
\hline 6. Test. sem capina & - & 0 & 0 & 0 & 0 & 0 & 0 & 0 & 0 & 0 & $5,7 \mathrm{~b}$ \\
\hline $\mathrm{C}, \mathrm{V},(\%)$ & - & 2,46 & 9,79 & 3,96 & 3,29 & 8,42 & 3,03 & 2,79 & 12,2 & 5,06 & 14,7 \\
\hline
\end{tabular}

Nas colunas, médias seguidas de mesma letra, não diferem significativamente pelo teste de Tukey (5\%).

*/ Percentual de controle dos herbicidas sobre plantas daninhas, onde $0 \%$ corresponde a "sem controle" e $100 \%$ a "controle total".

1/ Plantas daninhas controladas, onde (1) Brachiaria plantaginea (capim-papuã); (2) Digitaria horizontalis (capim-milhã); (3) Eleusine indica (capim pé-de-galinha), DAA= Dias após a aplicação.

$2 /$ i.a. $/$ ha $=$ ingrediente ativo aplicado por hectare

vel a ocupação e o sombreamento do solo, chega a inviabilizar a produção desta cultura, com atrofiamento de até $100 \%$ das raízes (Durigan, 1992). Blanco \& Oliveira (1971), considerando uma população de dicotiledôneas, em grau intenso de infestação competindo com a cultura, concluíram que o período de maior competição das plantas daninhas com a cenoura é de 20 dias, a partir da germinação desta cultura. $\mathrm{O}$ controle de plantas daninhas pode ser realizado com herbicidas pré ou pósemergentes, sendo que a partir de 20 dias após a emergência da cultura os danos proporcionados pelas plantas daninhas são menos acentuados. As plantas daninhas emergentes, após os 20 primeiros dias do ciclo da cultura, não provocam quedas na produção (Pitelli et al, 1976). Entre os herbicidas da ação pós-emergente registrados para uso em cenoura, encontra-se o fluazifop-p-butil, do grupo químico dos aril-oxi-fenoxipropionatos, que objetiva o controle de gramíneas anuais (Andrei, 1996). Do mesmo grupo químico, porém ainda em fase experimental para a cultura, encontra-se o herbicida propaquizafop, de ação graminicida (Rodrigues, 1995) e que pode representar em mais uma opção de controle. Neste sentido, realizouse o presente trabalho que teve como objetivo avaliar a eficiência e a seletividade dos herbicidas propaquizafop e fluazifop-p-butil no controle de plantas daninhas na cultura da cenoura, através da aplicação pós-emergente.

\section{MATERIAL E MÉTODOS}

Conduziu-se um experimento de campo no Município de Piraí do SulPR em solo de textura argilo-arenosa, no ano de 1995. Visou-se avaliar a eficiência dos herbicidas propaquizafop e fluazifop-p-butil no controle de plantas daninhas e sua seletividade à cultura da cenoura, quando aplicados em pósemergência. O delineamento experimental utilizado foi de blocos ao acaso, com seis tratamentos e quatro repetições. A área útil das parcelas foi de 5,0 $\mathrm{m}^{2}$. Os tratamentos utilizados foram: propaquizafop (Shogun $100 \mathrm{CE}$ ) nas doses de 100, 125 e $150 \mathrm{~g}$ i.a./ha + óleo mineral (OPPA BR a $0,5 \% \mathrm{v} / \mathrm{v}$ ), fluazifop-p-butil (Fusilade 125 BIW) na dose de $188 \mathrm{~g}$ i.a./ha, testemunha capinada e testemunha sem capina. A semeadura foi mecanizada, com espaçamento entre fileiras de $25 \mathrm{~cm}$, realizada em 15 de junho de 1995, utilizando-se a cultivar Nantes TimTom. A irrigação da cultura durante sua fase vegetativa foi por aspersão. A adubação básica consistiu da aplicação de $1.000 \mathrm{~kg} / \mathrm{ha}$ de adubo da fórmula 05-25-25. Os tratamentos foram aplicados no dia 14 de outubro de 1995, através de pulverizador de pressão constante à base de $\mathrm{CO}_{2}$ com bicos de jato leque XR 110.015. As avaliações de controle de plantas daninhas foram efetuadas visualmente aos 15, 30 e 45 dias após a aplicação dos tratamentos. A metodologia de avaliação utilizada foi a visual, a mais usual quando o número de plantas daninhas é elevado
(Sociedade Brasileira da Ciência das Plantas Daninhas, 1995; Velini, 1995). Assim, comparou-se o controle exercido pelos herbicidas com a testemunha sem capina, onde " $0 \%$ " correspondeu a "sem controle" e " $100 \%$ " a "controle total". Considerou-se eficiente o tratamento que apresentou, sobre cada espécie de planta daninha, porcentagem de controle igual ou superior a $80 \%$. As plantas daninhas predominantes no experimento foram capim-papuã, capimmilhã e capim pé-de-galinha, que no dia da aplicação apresentavam de 0 a 3 perfilhos. As plantas de cenoura, nesta data, encontravam-se com 4 a 5 folhas e 12 a $15 \mathrm{~cm}$ de altura. A colheita foi efetuada manualmente no dia 05 de dezembro de 1995.

\section{RESULTADOS E DISCUSSÃO}

Observou-se que o herbicida propaquizafop nas doses avaliadas, foi eficiente no controle sobre capim-papuã, apresentando controle acima de $90 \% \mathrm{em}$ todas as avaliações (Tabela 1). O controle resultante foi similar ao verificado para o fluazifop-p-butil. Sobre capimmilhã, observou-se que o herbicida propaquizafop foi eficiente no controle da invasora nas três doses utilizadas, em todas as datas de avaliação. Os resultados foram similares ao verificado para o tratamento com o produto padrão utilizado que, entretanto, apresentou controle de $75 \%$ na primeira e na terceira avaliação. No controle sobre capim péde-galinha, tanto o propaquizafop como 
o fluazifop-p-butil mostraram-se eficientes, com valores superiores a $86 \%$ para todas as doses utilizadas e em todas as datas de avaliação, resultados concordantes com os observados por Lorenzi (1994), que verificou controle eficiente do propaquizafop e do fluazifop-p-butil sobre capim-papuã, capim-milhã e capim pé-de-galinha. Nas três avaliações, observou-se que a maior eficiência dos produtos ocorreu sobre as invasoras com até dois perfilhos e as que "escaparam" do controle apresentavam de três a quatro perfilhos. Deve ser ressaltado, que em média menos de 5\% das plantas daninhas do ensaio apresentavam 4 perfilhos e estas, apesar de poucas, foram as que os produtos não conseguiram eliminar. Os tratamentos com herbicidas e a testemunha capinada apresentaram produção por parcela similar e superior à produção da testemunha sem capina. As perdas proporcionadas pela presença das plantas daninhas no experimento foram de $76,4 \%$, indicando a necessidade de controle para obtenção de produções adequadas. Quanto a fitotoxicidade, não foram observadas alterações na coloração e na altura das plantas de cenoura, que pudessem ser atribuídas aos produtos utilizados. Não houve diferença significativa na produção de raízes quando se comparou o controle de plantas daninhas através de herbicidas ao controle manual.

\section{LITERATURA CITADA}

ANDREI, E. Compendio de defensivos agrícolas. $5^{\mathrm{a}}$ ed. São Paulo: Andrei, 1996. 506 p.

BLANCO, H.G.; OLIVEIRA, D. de A. Duração do período de competição de plantas daninhas com a cultura da cenoura (Daucus carota L.). O Biológico, São Paulo, v. 37 n. 1, p. 3-7, 1971.

DURIGAN, J.C. Controle de plantas daninhas nas principais olerícolas: Umbelíferas e Cucurbitáceas. In: SIMPÓSIO NACIONAL SOBRE MANEJO INTEGRADO DE PLANTAS DANINHAS EM HORTALIÇAS. UNESP-Botucatu-SP/SOB/FEPAF, 1992, p. 157-186, 1992.
LORENZI, H. Manual de Identificação e Controle de Plantas Daninhas. $4^{\text {a }}$ ed. Nova Odessa-SP. Editora Plantarum, 1994.

PITELLI, R.A.; CHURATA MASCA, M.G.C.; OLIVEIRA, A.F. Competição entre plantas daninhas e a cultura da cenoura (Daucus carota L.) cv. Kuroda. In: SEMINÁRIO BRASILEIRO DE HERBICIDAS E ERVAS DANINHAS, 11. Londrina, 1976. Resumos... Londrina, 1976. p. 22.

RODRIGUES, B.N. Guia de Herbicidas. Benedito Noedi Rodrigues e Fernando Sousa de Almeida. 3. ed. Londrina-PR. 1995. 675 p.

SOCIEDADE BRASILEIRA DA CIÊNCIA DAS PLANTAS DANINHAS. Procedimentos para instalação, avaliação e análise de experimentos com herbicidas. Londrina: SBCPD, 1995. $42 \mathrm{p}$.

VELINI, E. Estudo e desenvolvimento de métodos experimentais e amostrais adaptados à matologia. Jaboticabal, FCA/UNESP. 1995. 250 p. (Tese doutorado). 